\title{
Early clinical predictors for the prognosis of invasive pneumococcal disease
}

Shuiyan $\mathrm{Wu}^{1+}$, Xubei Guo ${ }^{1 \dagger}$, Zhong Xu', Meilin Han¹, Lili Huang ${ }^{2}$, Yunzhen Tao ${ }^{2}$, Ying Li', Yanhong Li Tao Zhang ${ }^{4}$ and Zhenjiang Bai ${ }^{{ }^{*}}$

\begin{abstract}
Background: Risk factors related to mortality due to invasive pneumococcal disease (IPD) have been unveiled previously, but early clinical manifestations of IPD based on prognosis remain uncovered.

Methods: The demographic characteristics, clinical features, serotype, antibiotic susceptibility, and outcomes of 97 hospitalized children with laboratory-confirmed IPD from Suzhou, China, were collected and analyzed retrospectively.

Results: The median age was 0.69 (0.49-1.55) years in the non-survivor group compared with 2.39 (0.90-3.81) years in the survivor group. The mortality of 97 children with laboratory-confirmed IPD was 17.5\% (17/97), and 53.6\% of them were aged less than 2 years. Pathogens were mainly from the blood and cerebrospinal fluid, and sepsis was the most frequent type. Statistically significant differences were found in hyperpyrexia, vomiting, anorexia, lethargy, poor perfusion of extremities, $\mathrm{Hb}$ level, and PIt count between the nonsurvival and survival groups. Further, the multivariate regression analysis showed that early signs, including hyperpyrexia, vomiting, anorexia, lethargy, and poor perfusion of extremities, were independent risk factors for the in-hospital mortality of children with laboratory-confirmed IPD. The mortality was also associated with antimicrobial sensitivity in pneumococcal isolates. The microbes in 1/17 (5.9\%) children who were prescribed an antibiotic showed antimicrobial sensitivity in the nonsurvival group, compared with 21/80 (26.3\%) children who survived. The most common serotypes identified were $6 \mathrm{~B}(35.3 \%, 6 / 17), 14$ (23.5\%, 4/17), $19 F(23.5 \%, 4 / 17), 19 \mathrm{~A}(5.9 \%, 1 / 17), 23 \mathrm{~F}(5.9 \%, 1 / 17)$, and $20(5.9 \%, 1 / 17)$ in the nonsurvival group. The coverage of IPD serotypes of the 7-valent pneumococcal conjugate vaccine (PCV7) was $88.2 \%(15 / 17)$, while that of the 13-valent $S$. pneumoniae vaccine (PCV13) was $94.1 \%$ (16/17) of the coverage in the nonsurvival group.
\end{abstract}

Conclusions: Recurrent hyperpyrexia, vomiting, anorexia, lethargy, and poor perfusion of extremities in the early stage were independent predictors for the in-hospital mortality of children with laboratory-confirmed IPD. Appropriate use of antibiotics and PCV immunization were the keys to improve the outcome of IPD.

Keywords: Children, Invasive pneumococcal disease, Mortality, Risk factors, Serotype

\footnotetext{
* Correspondence: doctor1219@163.com

†Shuiyan Wu and Xubei Guo contributed equally to this work.

${ }^{1}$ Pediatric Intensive Care Unit, Children's Hospital of Soochow University,

Suzhou, Jiangsu, China

Full list of author information is available at the end of the article
}

(c) The Author(s). 2020 Open Access This article is licensed under a Creative Commons Attribution 4.0 International License, which permits use, sharing, adaptation, distribution and reproduction in any medium or format, as long as you give appropriate credit to the original author(s) and the source, provide a link to the Creative Commons licence, and indicate if changes were made. The images or other third party material in this article are included in the article's Creative Commons licence, unless indicated otherwise in a credit line to the material. If material is not included in the article's Creative Commons licence and your intended use is not permitted by statutory regulation or exceeds the permitted use, you will need to obtain permission directly from the copyright holder. To view a copy of this licence, visit http://creativecommons.org/licenses/by/4.0/ The Creative Commons Public Domain Dedication waiver (http://creativecommons.org/publicdomain/zero/1.0/) applies to the data made available in this article, unless otherwise stated in a credit line to the data. 


\section{Background}

Streptococcus pneumoniae (S. pneumoniae) infections are the leading cause of death from a vaccine-preventable illness in children aged less than 5 years, accounting for $18.3 \%$ of severe pneumonia and $33 \%$ of death caused by pneumonia [1]. S. pneumoniae can also cause invasive pneumococcal disease (IPD), including pneumonia, meningitis, osteomyelitis, and sepsis [2]. IPD is defined as a disease in which $S$. pneumoniae is cultured from normal sterile sites, such as blood, cerebrospinal fluid, pleural effusion, biopsy, joint effusion, or peritoneal effusion [3]. Previous reports found that pneumococcal conjugate vaccine $(\mathrm{PCV})$ immunization could effectively prevent IPD $[2,4,5]$. Therefore, vaccine immunization is an excellent strategy to reduce the incidence and mortality of IPD.

However, PCV immunization is not considered a routine vaccination by the government in many countries, especially China. Hence, the incidence and mortality are still high in these countries. Although Suzhou is one of the wealthiest cities in China, only $2-10 \%$ of patients were vaccinated during the study period. Many studies identified some features of in-hospital IPD in adults and children [6-9], but the initial clinical characteristics for prognosis were not reported. The symptoms and signs of IPD are related to many factors such as host immunity, S. pneumoniae virulence, and site of infection [10]. Early recognition and prompt diagnosis remain the challenges. The present study was performed to analyze the clinical features and outcomes of children, so as to find a better strategy for reducing the incidence and mortality of IPD within $24 \mathrm{~h}$ of the onset in China.

\section{Methods}

\section{Clinical data collection}

All children admitted to the pediatric intensive care unit of Children's Hospital of Soochow University with the isolation of $S$. pneumoniae from sterile sites (blood, pleural fluid, and cerebrospinal fluid) were included from January 2011 to December 2017. This study cohort comprised children aged $0.16-11.26$ years. None of them received a pneumococcal vaccine. Data of patients, including demographics, symptoms and signs, laboratory data, and empiric and definite antimicrobial agents within $24 \mathrm{~h}$ of the onset of the disease, were collected from the clinical records retrospectively. The patients were divided into drug-sensitivity-consistent and drugsensitivity-inconsistent groups depending on whether the antibiotic use was consistent with drug sensitivity. The details on the final diagnosis and outcome were also collected. All patients were divided into survival and nonsurvival (death) groups according to their survival within 30 days. The study procedures were conducted in accordance with the declaration of Helsinki. Written informed consent was obtained from the family involved. The study was reviewed by the Institutional Review Board in the hospital (ethics approval number: 2020CS069).

\section{Definitions}

The diagnosis of bacterial meningitis was according to the criteria of World Health Organization case definition [11]: (1) sudden onset of fever $\left(>38.5^{\circ} \mathrm{C}\right.$ rectal or $>$ $38.0^{\circ} \mathrm{C}$ axillary); (2) one of the following symptoms or signs: headache, altered consciousness, or meningeal irritation; (3) cerebrospinal fluid examination showing either of the following: leukocytosis $\left(>100 \times 10^{6}\right.$ cells/L) or leukocytosis $\left(10-100 \times 10^{6}\right.$ cells/L) with an elevated protein $(>100 \mathrm{mg} / \mathrm{dL})$ or decreased glucose $(<40 \mathrm{mg} / \mathrm{dL})$; and (4) positive culture, positive Gram stain, or positive bacterial antigen in the CSF. Patients who met diagnostic criteria $1,2,3$, and 4 were considered confirmed cases. The diagnosis of sepsis was according to the diagnostic criteria of "Surviving Sepsis Campaign: international guidelines for the management of severe sepsis and septic shock, 2012" [4]: fever (anal temperature $>38.5^{\circ} \mathrm{C}$ ) or hypothermia (anal temperature $<35^{\circ} \mathrm{C}$ ), tachycardia, and at least one of the following complications: consciousness change, hypoxemia, or elevated serum lactate levels. Shock, DIC, respiratory failure, poor perfusion of extremities, and acute kidney injury (AKI) were diagnosed by physicians according to the criteria described previously $[4,12,13]$.

\section{Specimen acquisition and strain isolation}

Clinical specimens were collected at admission, including blood, cerebrospinal fluid, and pleural effusion. The cerebrospinal fluid was collected from children with suspected central infections, and pleural effusion was collected from children with pleural effusion. Once the specimen was obtained, it was immediately sent to the microbiology laboratory. Bacterial isolation and culture were carried out according to the "National Clinical Laboratory Procedures" for clinical microbiological testing [14]. The obtained bacteria were subjected to Gram staining, and the morphology of the bacteria was observed. The optochin sensitivity test was used, and the bile solubility test was used as an auxiliary identification test.

\section{Drug susceptibility test}

The bacteria in the logarithmic growth phase after isolating colonies were adjusted. The optical density value was adjusted to 0.5 McFarland Standard with physiological saline, and the minimal inhibitory concentration value was determined according to the operational instructions of the $S$. pneumoniae susceptibility kit (Biomerieux, France) [14]. The size of the rifampicin and linezolid inhibition zone was measured by the KirbyBauer disk diffusion method. The size of the inhibition zone was interpreted in accordance with the CLSI2012 
standard. The quality control was $S$. pneumoniae ATCC49619, which was purchased from the Clinical Testing Center of the Ministry of Health of China.

\section{Serotyping of S. pneumoniae}

The serotypes of all isolates were typed with a capsulequelling test using type-specific antisera (Statens Serum Institute, Copenhagen, Denmark). The experimental procedure was carried out as previously described [15].

\section{Statistical analysis}

Data were analyzed using SPSS 22.0 software. The normal-distribution measurement data were expressed as mean \pm standard deviation $(x \pm s)$. The two groups were compared using the $t$ test, $\chi^{2}$ test, or exact probability method. The nonnormal-distribution data were expressed by the quartile method and compared using the Mann-Whitney $U$ test. A $P$-value of less than 0.05 was considered statistically significant.

\section{Results}

\section{Demographics}

The median age of 97 children with laboratoryconfirmed IPD was $1.88(0.78-3.64)$ years. The mortality rate was $17.5 \%$ (17/97); 91.8\% (89/97) were aged less than 5 years, and $53.6 \%(52 / 97)$ were aged less than 2 years. The nonsurvival group $(n=17)$ comprised $100 \%$ $(17 / 17)$ aged less than 5 years and $82.4 \%(14 / 17)$ aged less than 2 years. The median age of the patients in the nonsurvival group was $0.69(0.49-1.55)$ years, significantly less than $2.39(0.90-3.81)$ years in the survival group $(n=80)(P=0.001)$. The median age of patients in the meningitis group $(n=46)$ was $0.99(0.64-2.35)$ years, significantly less than $2.78(1.09-3.52)$ years in the nonmeningitis group $(n=51) \quad(P=0.031)$. The median age was $1.54(0.76-3.44)$ years in the sepsis group $(n=86)$ and $1.36(0.73-2.31)$ years in the non-sepsis group $(n=$ 11) $(P=0.065)$.

\section{Clinical manifestations}

Among the 97 specimens, blood culture specimens accounted for 61 patients $(61 / 97,62.9 \%)$, cerebrospinal fluid culture specimens for 27 patients (27/97, 27.8\%), and pleural effusion culture specimens for 9 patients (9/ 97, 9.3\%). Further, 42 patients had sepsis alone, 35 had sepsis with meningitis, 9 had sepsis with severe pneumonia, 1 had sepsis with osteomyelitis, and 11 had meningitis alone.

The incidence rates of hyperpyrexia (temperature more than $40^{\circ} \mathrm{C}$ ), vomiting (greater than three times a day), anorexia ( $50 \%$ less than usual), lethargy, and poor perfusion of extremities among nonsurvivors compared with survivors were $41 \%$ vs $12,70 \%$ vs $30,94 \%$ vs 60 , $94 \%$ vs 36 , and $76 \%$ vs $12 \%$, respectively, which were significantly higher in the nonsurvival group than in the survival group within $24 \mathrm{~h}$ of the onset of the disease (Table 1). Hemoglobin ( $\mathrm{Hb})$, platelet (Plt) count, white blood cell count, and neutropenia levels were $94.29 \pm$ 25.74, $215.07 \pm 158.07,8.45 \pm 8.42$ and $6.10 \pm 6.62$ in the nonsurvival group, and $110.42 \pm 19.23,352.06 \pm 164.66$, $19.74 \pm 22.67$, and $66.67 \pm 19.26$ in the survival group. The nonsurvival group had significantly lower hemoglobin $(\mathrm{Hb})$ level and Plt count compared with the survival group. However, the C-reactive protein level was not statistically different between the two groups $(P=0.968)$ (Table 1).

The multivariate regression analysis showed that hyperpyrexia, vomiting, lethargy, and poor perfusion of extremities were independent risk factors for the inhospital mortality of children with IPD (Table 2). The

Table 1 Comparison of clinical manifestations between nonsurvivors and survivors of children with IPD

\begin{tabular}{|c|c|c|c|}
\hline Clinical information & Death, $n=17$ & Survival, $n=80$ & $P$ \\
\hline Age(y) & $0.69(0.49,1.55)$ & $2.39(0.90,3.81)$ & 0.001 \\
\hline Male & $11(64.7 \%)$ & $45(56.2 \%)$ & 0.522 \\
\hline PRISMIII score & $21.04 \pm 10.09$ & $6.78 \pm 12.32$ & 0.000 \\
\hline \multicolumn{4}{|l|}{ Symptoms and signs } \\
\hline Hyperpyrexia & $7(41.2 \%)$ & $10(12.5 \%)$ & $0.010^{*}$ \\
\hline Vomiting & $12(70.6 \%)$ & $24(30.0 \%)$ & 0.002 \\
\hline Anorexia & $16(94.1 \%)$ & $48(60.0 \%)$ & 0.007 \\
\hline Lethargy & $16(94.1 \%)$ & $29(36.3 \%)$ & 0.000 \\
\hline Oliguria & $4(23.5 \%)$ & $12(15.0 \%)$ & $0.295^{*}$ \\
\hline Poor perfusion of extremities & $13(76.5 \%)$ & $10(12.5 \%)$ & $0.000^{*}$ \\
\hline Disease category & & & 0.000 \\
\hline Sepsis & 0 & 42 & \\
\hline Sepsis with meningitis & 17 & 18 & \\
\hline Meningitis alone & 0 & 11 & \\
\hline Sepsis with pneumonia & 0 & 9 & \\
\hline Source of pathogens & & & 0.083 \\
\hline Blood & 9 & 52 & \\
\hline Cerebrospinal fluid & 8 & 19 & \\
\hline Pleural effusion & 0 & 9 & \\
\hline \multicolumn{4}{|l|}{ Laboratory results } \\
\hline $\mathrm{Hb}(\mathrm{g} / \mathrm{L})$ & $94.29 \pm 25.74$ & $110.42 \pm 19.23$ & 0.006 \\
\hline $\mathrm{WBC}\left(\times 10^{9} / \mathrm{L}\right)$ & $8.45 \pm 8.42$ & $19.74 \pm 22.67$ & 0.071 \\
\hline $\mathrm{N} \#\left(\times 10^{9} / \mathrm{L}\right)$ & $6.10 \pm 6.62$ & $66.67 \pm 19.26$ & 0.052 \\
\hline $\mathrm{L} \#\left(\times 10^{9} / \mathrm{L}\right)$ & $29.48 \pm 17.17$ & $24.91 \pm 17.34$ & 0.478 \\
\hline $\operatorname{Plt}\left(\times 10^{9} / \mathrm{L}\right)$ & $215.07 \pm 158.07$ & $352.06 \pm 164.66$ & 0.005 \\
\hline CRP (mg/L) & $40.20 \pm 66.69$ & $47.42 \pm 69.43$ & 0.968 \\
\hline
\end{tabular}

Hyperpyrexia: fever over $40^{\circ} \mathrm{C}$; vomiting: greater than 3 times/d; anorexia: $50 \%$ less than of usual; $H b$ hemoglobin, $N \#$ neutrophil absolute value, $L \#$ lymphacyte absolute value, CRP C-reactive protein ${ }^{*}$ Calculated using Fisher's exact test 
Table 2 Multiple logistic regression analyses of early clinical manifestations potentially associated with in-hospital mortality

\begin{tabular}{lll}
\hline & \multicolumn{2}{l}{ Multivariate logistic regression } \\
\cline { 2 - 3 } & OR(95\%Cl) & $P$ value \\
\hline Age $(y)$ & $1.649(0.439,1.187)$ & $0.199^{\mathrm{a}}$ \\
PRISMIII score & $7.591(1.028,1.179)$ & $0.006^{\mathrm{b}}$ \\
Hyperpyrexia & $5.372(1.294,21.710)$ & $0.020^{c}$ \\
Vomiting & $6.013(1.023,26.522)$ & $0.014^{c}$ \\
Lethargy & $9.633(3.166,164.297)$ & $0.002^{c}$ \\
Poor perfusion of extremities & $8.348(1.910,36.485)$ & $0.001^{c}$ \\
\hline
\end{tabular}

Hyperpyrexia: fever over $40^{\circ} \mathrm{C}$; vomiting: greater than 3 times $/ \mathrm{d}$; $\mathrm{Cl}$ confidence interval, $O R$ odds ratio

a after adjustment for PRISMIII score

bafter adjustment for age

cafter adjustment for age and PRISMIII score

pediatric risk of mortality III (PRISM III) score was significantly higher in the nonsurvival group than in the survival group (Table 2). Shock, respiratory failure, AKI, and convulsions or coma in the early stage were rare, and therefore statistical analysis was not done. Two patients died and two were alive with shock, three patients died and one was alive with respiratory failure, and two patients died and one was alive with seizure. Only one patient showed AKI in the nonsurvival group.

\section{Selection of antibiotics}

The frequency of antibiotic use was as follows: azithromycin 30.2\% (19/63), cefazolin 17.5\% (11/63), oxycephalosporin $15.9 \% \quad(10 / 63)$, ceftriaxone $12.7 \% \quad(8 / 63)$, cefonicid $11.1 \%$ (7/63), cefodizime $9.5 \%$ (6/63), ceftizoxime $9.5 \%(6 / 63)$, cefoxitin $7.9 \%(5 / 63)$, and cefuroxime $6.3 \%(4 / 63)$. The consistency between the choice of antibiotics and the drug sensitivity test was $22.7 \%(22 / 97)$. The rationality of antibiotic choice was $5.9 \%$ in the nonsurvival group, which was lower than $26.3 \%$ in the survival group $(P=0.050)$ (Table 3$)$. Besides, a comparison of the percentage of antibiotic change in survivors and nonsurvivors showed a high frequency of antibiotic replacement ( $88 \%$ vs $94 \%, P=0.261)$. The outcome was not related to the use of antibiotics orally or intravenously. The resistance rate in 97 cases of S. pneumoniae was $100 \%(97 / 97)$ to erythromycin, $97.9 \%$ (95/97) to clindamycin, $87.6 \%$ (85/97) to tetracycline, $72.2 \%$ (70/97) to sulfamethoxazole, $49.5 \%$ (48/97) to penicillin, $33.0 \%$
(32/97) to cefotaxime, $8.2 \%$ (8/97) to amoxicillin, 5.2\% (5/97) to chloramphenicol, $0.0 \%(0 / 80)$ to vancomycin, and $0.0 \%(0 / 80)$ to levofloxacin.

\section{Serotype analysis}

Ten serotypes of $S$. pneumoniae were detected in 97 hospitalized children with laboratory-confirmed IPD, followed by $6 \mathrm{~B}(24.7 \%, 24 / 97), 14(20.6 \%, 20 / 97), 19 \mathrm{~F}$ (18.6\%, 18/97), 19A (15.5\%, 15/97), 23F (7.2\%, 7/97), $9 \mathrm{~V}$ (5.2\%, 5/97), $20(4.1 \%, 4 / 97), 15 \mathrm{~B} / \mathrm{C}(2.1 \%, 2 / 97), 6 \mathrm{~A}$ $(1.0 \%, 1 / 97)$, and $4(1.0 \%, 1 / 97)$. However, six serotypes including $6 \mathrm{~B}(35.3 \%, 6 / 17), 14(23.5 \%, 4 / 17), 19 \mathrm{~F}(23.5 \%$, $4 / 17), 19 \mathrm{~A}(5.9 \%, 1 / 17), 23 \mathrm{~F}(5.9 \%, 1 / 17)$, and $20(5.9 \%$, $1 / 17$ ) in nonsurvivors. No significant correlation was found between serotypes and vomiting, anorexia, drowsiness and shock, respiratory failure, AKI, convulsion, and coma. Moreover, no significant correlation was observed between serotypes and mortality and PRISMIII score.

Further, none of the 97 children with laboratoryconfirmed IPD received a pneumococcal vaccine. The 7valent PCV (PCV7) covered 77.3\% (75/97) of the IPD serotype, which was significantly lower than $93.8 \%$ (91/ 97) of the 13-valent PCV (PCV13). The 7-valent $S$. pneumoniae vaccine (PCV7) covered $88.2 \%(15 / 17)$ of nonsurvivors, while 13-valent $S$. pneumoniae vaccine (PCV13) covered 94.1\% (16/17) (Table 4).

\section{Discussion}

In this study, the median age of hospitalized children with laboratory-confirmed IPD was only 1.88 (0.783.64) years, accounting for $53.6 \%$ aged less than 2 years. The median age of 17 nonsurvivors was only 0.69 years, accounting for $82.4 \%$ aged less than 2 years. According to the reports on high-income countries, the annual incidence of IPD in children aged less than 2 years was $160 / 100,000$ [16], indicating that these children were at high risk of S. pneumoniae infection. Additional studies showed S. pneumoniae infection in infants from Papua New Guinea and Australia [17, 18]. Moreover, approximately half of children from Sweden and the United States were infected with $S$. pneumoniae at least once before the age of 2 years $[19,20]$; these results were the same as the present findings. The predisposing factors of this population were not fully understood. It was speculated that the infection might be related to the immature

Table 3 Comparison of rationality of antibiotic choice between non-survivors and survivors of children with IPD

\begin{tabular}{|c|c|c|c|}
\hline Events about antibiotic choice & Death & Survival & $P$ \\
\hline whether used antibiotics & $12 / 17(70.6 \%)$ & $52 / 80(65.0 \%)$ & 0.288 \\
\hline whether used antibiotics intravenously & 10/14 (71.4\%) & $45 / 80(56.3 \%)$ & $0.840^{\circ}$ \\
\hline whether the choice of antibiotics is consistent with drug susceptibility & $1 / 17(5.9 \%)$ & $21 / 80(26.3 \%)$ & 0.050 \\
\hline percentage of antibiotic change & $15 / 17(88.2 \%)$ & $75 / 80(93.8 \%)$ & 0.261 \\
\hline
\end{tabular}

*Calculated using Fisher's exact test 
Table 4 Serotype distribution analysis between the two groups

\begin{tabular}{llll}
\hline & Death, $n=17$ & Survival, $n=80$ & Total \\
\hline PCV7 serptypes & 6 & 18 & 75 \\
$6 \mathrm{~B}$ & 4 & 16 & 24 \\
14 & 4 & 14 & 20 \\
$19 \mathrm{~F}$ & 1 & 6 & 18 \\
$23 \mathrm{~F}$ & 0 & 1 & 7 \\
4 & 0 & 5 & 1 \\
$9 \mathrm{~V}$ & & & 5 \\
PCV13 serotypes not included & & & 16 \\
in PCV7 & & 1 & 1 \\
$6 \mathrm{~A}$ & 0 & 14 & 15 \\
$19 \mathrm{~A}$ & 1 & 0 & 0 \\
3 & 0 & & 6 \\
Others & & 3 & 4 \\
20 & 1 & 2 & 2 \\
$15 B / C$ & 0 & & \\
\hline
\end{tabular}

immune system of infants and young children [21]. Therefore, it is recommended internationally to inoculate a four-time vaccination strategy of the PCV13 for individuals aged 2, 4, 6, and 12-15 months, and before the age of 2 years [5].

Furthermore, children who died of IPD showed more nonspecific symptoms, such as recurrent hyperpyrexia, vomiting, lethargy, and poor perfusion of extremities in the early stage. Some vigilance and close observation of children with nonspecific symptoms in the early stage are required to deal with the progression of the disease. This study found that $43.7 \%$ (45/97) patients had a change in consciousness during admission, which was higher than that in $11.5 \%$ of other patients with pneumonia [22]. All of the nonsurvivors were diagnosed with sepsis with meningitis, and therefore these signs might indicate increased intracranial pressure (IICP). S. pneumoniae results not only in disruption of the blood-brain barrier but also in vascular and neuronal injury, finally leading to IICP $[22,23]$. Except for early antibiotic use, aggressive control of IICP is also important [24]. Previous studies showed that corticosteroid treatment reduced the death rate of patients with meningitis and $S$. pneumonia infection [25]. Therefore, close monitoring of the child's state is of great significance for the timely and effective treatment and prognosis of IPD.

The initial consistency rate between antibiotic selection and drug sensitivity was only $22.7 \%$. The rationality of antibiotic choice in the survival group was $26.3 \%$, which was about four times that in the nonsurvival group. It also suggested a trend toward the impact of a reasonable selection of early antibiotics on mortality. In the present study, the resistance rate of $S$. pneumoniae was $100 \%$ to erythromycin, $49.5 \%$ to penicillin, $33.0 \%$ to cefotaxime, $8.2 \%$ to amoxicillin, and $0 \%$ to vancomycin or levofloxacin. The strains of nonsurvivors in this study were multi-drug resistant. Domestic and foreign reports also showed that $S$. pneumoniae was generally multidrug resistant, and the resistance to penicillin and cephalosporins increased [6, 26, 27]. Compared with drug sensitivity analysis in the present study, a better consistency rate was achieved if the choice of antibiotics strictly abided by China's "Guidelines for the Management of Community Communicable Pneumonia (2013 Revision)". The results suggested that physicians should be encouraged to follow a standard protocol based on the local patterns of antimicrobial sensitivity for community-acquired infection with modifications in the hospital as needed following the documentation of antimicrobial resistance patterns [28].

Ten serotypes of S. pneumoniae were detected in 97 hospitalized children with laboratory-confirmed IPD and 6 serotypes in nonsurvivors; 6B was the leading serotype, followed by 14, 19F, 19A, and 23F, which were similar to the top 5 serotypes in the other cities in China, but the sequence was different. The serotypes of IPD cases in the multicenter study of Chinese hospitals were 19F, 14, $19 \mathrm{~A}, 6 \mathrm{~B}$, and $23 \mathrm{~F}[29,30]$. In this study, the PCV13 could cover $93.8 \%$ of serotypes of IPD cases and $94.1 \%$ of nonsurvivors. A large number of studies also showed that PCV13 had a good coverage for the serotypes of IPD. The widespread vaccination of PCV13 in many countries has effectively reduced the incidence and mortality of IPD [31, 32]. At present, China's PCV13 has not been included in the first-line vaccination catalog. Moreover, this vaccine is expensive (800 RMB/dose, approximately $114 \$$ /dose). Therefore, very few children receive the PCV13 vaccine. About $2-10 \%$ of patients were vaccinated during the study period in Suzhou. The high coverage rate of PCV13 indicated that PCV13 could prevent pneumococcal diseases effectively. Unfortunately, none of the children with IPD were vaccinated with PCV13 or PCV7 vaccine in this study. Therefore, PCV13 should be underscored as an agent for preventable mortality in young children (particularly those less than 2 years of age), and thus should be adopted as part of the routine immunization schedule in China.

The present study had several limitations. First, the data of illness onset and presentation to hospital between survivors and nonsurvivors were not specified. So, their influence on the results could not be ruled out. Second, this was a retrospective, single-center study, and the sample size was limited. These factors reduced the strength of the findings. In addition, due to falsenegative culture results, some true IPD cases were not included. Next-generation sequencing might improve the diagnostic yield. More large-scale, comprehensive 
clinical studies and highly sensitive techniques are needed to confirm the conclusions.

\section{Conclusions}

In short, a majority of nonsurvivors with laboratoryconfirmed IPD were always younger than 2 years. Early signs, including recurrent hyperpyrexia, vomiting, lethargy, and poor perfusion of extremities, were the poor predictors of the outcome of laboratory-confirmed IPD. Inappropriate use of antibiotics for invasive pneumococcal infection and the low rate of PCV immunization in China were responsible for the high mortality of laboratory-confirmed IPD.

\section{Abbreviations}

SP: Streptococcus pneumoniae; IPD: Invasive pneumococcal disease; PCV: Pneumococcal conjugate vaccine

\section{Acknowledgements}

We thank International Science Editing (http://www.internationalscienceediting. com) for editing this manuscript.

\section{Authors' contributions}

$X G, Z X, M H, L H, Y T$ : acquisition of data, or analysis and interpretation of data. SW, ZB: designed and drafted the work and substantively revised it for content. YL1, TZ: made contributions to the conception. YL2: interpretation of data. All authors have approved the submitted version and agreed both to be personally accountable for the author's own contributions and to ensure that questions related to the accuracy or integrity of any part of the work.

\section{Funding}

Design of the study and collection, analysis and interpretation of data by fund from Suzhou Science and Technology Development Project (SYS201757) and the fifth batch of Gusu health person training project (GSWS2019050). Writing the manuscript was supported by the Natural science Foundation of Jiangsu Higher Education Institutions of China (18KJB320022).

\section{Availability of data and materials}

The datasets used and/or analysed during the current study are available from the corresponding author on reasonable request.

\section{Ethics approval and consent to participate}

The study was approved by the Research Ethics Committee of Children's Hospital of Soochow University (ethics approval number: 2020CS069). Informed written consent to participate was obtained from the parents/ guardians of the minors included in this study.

\section{Consent for publication}

Not applicable.

\section{Competing interests}

The authors declare no competing interests.

\section{Author details}

${ }^{1}$ Pediatric Intensive Care Unit, Children's Hospital of Soochow University, Suzhou, Jiangsu, China. 'Laboratory department, Children's Hospital of Soochow University, Suzhou, Jiangsu, China. ${ }^{3}$ Nephrology department, Children's Hospital of Soochow University, Suzhou, Jiangsu, China. ${ }^{4}$ Key Laboratory of Public Health Safety, Ministry of Education-department of Epidemiology, School of Public Health, Fudan University, Shanghai, China.
Received: 3 April 2020 Accepted: 30 August 2020

Published online: 04 September 2020

\section{References}

1. Walker CLF, Rudan I, Liu L, Nair H, Theodoratou E, Bhutta ZA, O'Brien KL, Campbell $H$, Black RE. Global burden of childhood pneumonia and diarrhoea. Lancet. 2013:381(9875):1405-16.

2. Prevention of pneumococcal disease: recommendations of the Advisory Committee on Immunization Practices (ACIP). MMWR Recomm Rep. 1997; 46(RR-8):1-24

3. Marrie TJ, Tyrrell GJ, Majumdar SR, Eurich DT. Invasive pneumococcal disease: still lots to learn and a need for standardized data collection instruments. Can Respir J. 2017:2017:2397429.

4. Dellinger RP, Levy MM, Rhodes A, Annane D, Gerlach H, Opal SM, Sevransky JE, Sprung CL, Douglas IS, Jaeschke $R$, et al. Surviving Sepsis campaign: international guidelines for management of severe sepsis and septic shock, 2012. Intensive Care Med. 2013;39(2):165-228.

5. Nuorti JP, Whitney CG, Centers for Disease C, Prevention. Prevention of pneumococcal disease among infants and children - use of 13-valent pneumococcal conjugate vaccine and 23-valent pneumococcal polysaccharide vaccine - recommendations of the Advisory Committee on Immunization Practices (ACIP). MMWR Recomm Rep. 2010:59(RR-11):1-18.

6. Ding Y, Geng Q, Tao Y, Lin Y, Wang Y, Black S, Zhao G, Zhang T. Etiology and epidemiology of children with acute otitis media and spontaneous otorrhea in Suzhou, China. Pediatr Infect Dis J. 2015;34(5):e102-6.

7. Hausdorff WP, Bryant J, Paradiso PR, Siber GR. Which pneumococcal serogroups cause the most invasive disease: implications for conjugate vaccine formulation and use, part I. Clin Infect Dis. 2000;30(1):100-21.

8. Rudan I, Chan KY, Zhang JS, Theodoratou E, Feng XL, Salomon JA, Lawn JE, Cousens S, Black RE, Guo Y, et al. Causes of deaths in children younger than 5 years in China in 2008. Lancet. 2010;375(9720):1083-9.

9. Martinez-Vega R, Jauneikaite E, Thoon KC, Chua HY, Huishi Chua A, Khong WX, Tan BH, Low Guek Hong J, Venkatachalam I, Anantharajah Tambyah P, et al. Risk factor profiles and clinical outcomes for children and adults with pneumococcal infections in Singapore: a need to expand vaccination policy? PLoS One. 2019;14(10):e0220951.

10. Hsieh YC, Lee WS, Shao PL, Chang LY, Huang LM. The transforming Streptococcus pneumoniae in the 21st century. Chang Gung Med J. 2008; 31(2):117-24.

11. Mclntosh ED, Reinert RR. Global prevailing and emerging pediatric pneumococcal serotypes. Expert Rev Vaccines. 2011;10(1):109-29.

12. Kudo D, Kushimoto S, Miyagawa N, Sato T, Hasegawa M, Ito F, Yamanouchi $\mathrm{S}$, Honda $\mathrm{H}$, Andoh K, Furukawa $\mathrm{H}$, et al. The impact of organ dysfunctions on mortality in patients with severe sepsis: a multicenter prospective observational study. J Crit Care. 2018;45:178-83.

13. Lima AP, Beelen P, Bakker J. Use of a peripheral perfusion index derived from the pulse oximetry signal as a noninvasive indicator of perfusion. Crit Care Med. 2002:30(6):1210-3.

14. Diawara I, Barguigua A, Katfy K, Nayme K, Belabbes H, Timinouni M, Zerouali K, Elmdaghri N. Molecular characterization of penicillin non-susceptible Streptococcus pneumoniae isolated before and after pneumococcal conjugate vaccine implementation in Casablanca, Morocco. Ann Clin Microbiol Antimicrob. 2017;16(1):23.

15. Sorensen UB. Typing of pneumococci by using 12 pooled antisera. J Clin Microbiol. 1993:31(8):2097-100.

16. Bechini A, Boccalini S, Bonanni P. Immunization with the 7-valent conjugate pneumococcal vaccine: impact evaluation, continuing surveillance and future perspectives. Vaccine. 2009;27(25-26):3285-90.

17. Montgomery JM, Lehmann D, Smith T, Michael A, Joseph B, Lupiwa T, Coakley C, Spooner V, Best B, Riley ID, et al. Bacterial colonization of the upper respiratory tract and its association with acute lower respiratory tract infections in Highland children of Papua New Guinea. Rev Infect Dis. 1990; 12(Suppl 8):S1006-16.

18. Leach AJ, Boswell JB, Asche V, Nienhuys TG, Mathews JD. Bacterial colonization of the nasopharynx predicts very early onset and persistence of otitis media in Australian Aboriginal infants. Pediatr Infect Dis J. 1994; 13(11):983-9.

19. Faden H, Duffy L, Wasielewski R, Wolf J, Krystofik D, Tung Y. Relationship between nasopharyngeal colonization and the development of otitis media in children. Tonawanda/Williamsville pediatrics. J Infect Dis. 1997;175(6): 1440-5. 
20. Backhaus E, Berg S, Andersson R, Ockborn G, Malmstrom P, Dahl M, Nasic S, Trollfors B. Epidemiology of invasive pneumococcal infections: manifestations, incidence and case fatality rate correlated to age, gender and risk factors. BMC Infect Dis. 2016;16:367.

21. van den Heuvel D, Jansen MAE, Nasserinejad K, Dik WA, van Lochem EG, Bakker-Jonges LE, Bouallouch-Charif H, Jaddoe WW, Hooijkaas H, van Dongen JJM, et al. Effects of nongenetic factors on immune cell dynamics in early childhood: the generation R study. J Allergy Clin Immunol. 2017; 139(6):1923-34 e1917.

22. Radetsky M. Fulminant bacterial meningitis. Pediatr Infect Dis J. 2014;33(2): 204-7.

23. Kastenbauer S, Pfister HW. Pneumococcal meningitis in adults: spectrum of complications and prognostic factors in a series of 87 cases. Brain. 2003; 126(Pt 5):1015-25.

24. Mook-Kanamori BB, Geldhoff $M$, van der Poll T, van de Beek D. Pathogenesis and pathophysiology of pneumococcal meningitis. Clin Microbiol Rev. 2011; 24(3):557-91.

25. Brouwer MC, McIntyre P, Prasad K, van de Beek D. Corticosteroids for acute bacterial meningitis. Cochrane Database Syst Rev. 2015;2015(9):CD004405.

26. Barlam TF, Morgan JR, Kaplan WA, Outterson K, Pelton SI. Disproportionate exposure to antibiotics in children at risk for invasive pneumococcal disease: potential for emerging resistance and opportunity for antibiotic stewardship. J Pediatr Infect Dis Soc. 2019;8(1):63-5.

27. Tin Tin Htar M, Christopoulou D, Schmitt HJ. Pneumococcal serotype evolution in Western Europe. BMC Infect Dis. 2015;15:419.

28. Subspecialty Group of Respiratory Diseases TSoPCMA, Editorial Board CJoP. [Guidelines for management of community acquired pneumonia in children (the revised edition of 2013) (I)]. Zhonghua Er Ke Za Zhi. 2013;51(10):745-752.

29. Hung IF, Tantawichien T, Tsai YH, Patil S, Zotomayor R. Regional epidemiology of invasive pneumococcal disease in Asian adults: epidemiology, disease burden, serotype distribution, and antimicrobial resistance patterns and prevention. Int J Infect Dis. 2013;17(6):e364-73.

30. Qian J, Yao K, Xue L, Xie G, Zheng Y, Wang C, Shang Y, Wang H, Wan L, Liu $L$, et al. Diversity of pneumococcal surface protein $A(P s p A)$ and relation to sequence typing in Streptococcus pneumoniae causing invasive disease in Chinese children. Eur J Clin Microbiol Infect Dis. 2012;31 (3):217-23.

31. Waight PA, Andrews NJ, Ladhani NJ, Sheppard CL, Slack MP, Miller E. Effect of the 13-valent pneumococcal conjugate vaccine on invasive pneumococcal disease in England and Wales 4 years after its introduction: an observational cohort study. Lancet Infect Dis. 2015;15(6):629.

32. Isaacman DJ, Mclntosh ED, Reinert RR. Burden of invasive pneumococcal disease and serotype distribution among Streptococcus pneumoniae isolates in young children in Europe: impact of the 7-valent pneumococcal conjugate vaccine and considerations for future conjugate vaccines. Int J Infect Dis. 2010;14(3):e197-209.

\section{Publisher's Note}

Springer Nature remains neutral with regard to jurisdictional claims in published maps and institutional affiliations.

Ready to submit your research? Choose BMC and benefit from:

- fast, convenient online submission

- thorough peer review by experienced researchers in your field

- rapid publication on acceptance

- support for research data, including large and complex data types

- gold Open Access which fosters wider collaboration and increased citations

- maximum visibility for your research: over $100 \mathrm{M}$ website views per year

At BMC, research is always in progress.

Learn more biomedcentral.com/submissions 